\title{
The Impact of Recommendation System Overuse on the Subjective Wellbeing of Internet Users
}

\author{
Morrant Hemans ${ }^{1}$, Dickson Kofi Wiredu Ocansey ${ }^{2,3}$ \\ ${ }^{1}$ School of Management, Jiangsu University, Zhenjiang 212013, Jiangsu, P.R. China. \\ ${ }^{2}$ Key Laboratory of Medical Science and Laboratory Medicine of Jiangsu Province, School of Medicine, Jiangsu \\ University, Zhenjiang 212013, Jiangsu, P.R. China. \\ ${ }^{3}$ Directorate of University Health Services, University of Cape Coast, Cape Coast, Ghana.
}

Article Info

Volume 8 Issue 1

Page Number: 239-247

Publication Issue :

January-February-2021

\section{Article History}

Accepted : 20 Feb 2021

Published : 28 Feb 2021

\section{ABSTRACT}

The stress in identifying useful information on the internet facilitated the use of recommendation systems by e-commerce and social network platforms to help users find their interested information quickly. However, this study seeks to investigate the impact of recommendation system overuse on the subjective wellbeing of internet users. The study reviewed previous studies in developing a research framework from the SOBC model that identifies social media overload as a (Situation) that triggers the intentions of internet users (Organism) to excessively use recommendation systems on the internet based on their level of self-concept clarity (Behavior) which (Consequently) affect their subjective wellbeing. SmartPLS 3.0 and SPSS v.22 software were deployed to analyze the research data and discover links between the constructs. The obtained results of the study confirm that, overuse of online recommendation systems negatively affect users' subjective wellbeing.

Keywords : Internet, Social Media Overload, Recommendation System Overuse, Self-Concept Clarity, Subjective Wellbeing

\section{INTRODUCTION}

The rapid growth of social media, mobile apps, sensing devices, and the Internet of Things (IoT) has resulted in a huge increase in data (Hadj Sassi et al., 2019). The explosion in the amount of digital information accessible and the number of Internet users has created a possible problem of information overload, which makes timely access to things of interest on the Internet difficult (Isinkaye et al., 2015).
In order to help users find their information quickly, effective tools in real-world applications are in great demand. As a result, a number of recommender systems have emerged, such as recommender systems for movies, books, friends, collaborators, and so forth (Hu et al., 2015; Zhao et al., 2020).

To cope with the vast amount of knowledge available on the Internet, recommender systems have become essential tools (Ramos et al., 2020; Ricci et al., 2015). 
According to Sharma \& Gera (2013), recommender systems are a type of information filtering system that attempts to predict a user's "rating" or "preference" for an item (such as music, books, or movies) or social element (e.g. people or groups) that they have not yet considered, by using a model based on the item's characteristics (content-based approaches) or the user's social setting (collaborative filtering approaches).

Previous research indicates that people with unclear self-perceptions are more focused on, or affected by, external stimuli (Smith et al., 1996). Therefore, we conclude that people who are more confused about different aspects of their lives, such as their beliefs and skills, are more likely to overuse recommendation systems on the various sites of e-commerce and social networks. Such people are said to have low selfconcept clarity because they are prone to selfconfusion and concomitant anxiety (Mittal, 2015). Self-concept clarity is characterized as "the degree to which the content of the self-concept of an individual (e.g. perceived personal attributes) is clearly and confidently defined, internally consistent and temporally stable"(Campbell et al., 1996). To explain further, one person may have a high degree of selfconcept clarity, indicating that she is reasonably sure about the different aspects of her self-concept; while another person may be low in clarity of self-concept, meaning that he is much less certain of the content and stability of his self-concept (Butzer \& Kuiper, 2006).

Because daily experiences are a significant indicator of subjective well-being (Liu et al., 2015; Tov, 2012) it is probable that overuse of recommendation systems by internet users with low self-concept clarity would influence their subjective well-being (SWB). Subjective well-being (SWB) is what most individuals refer to as happiness (Luhmann, 2017). According to Slocum-Gori et al. (2009), subjective well-being refers, to a positive orientation towards life and is normally focused on emotions such as happiness, morality, positive effects, and satisfaction with life.

Despite the plethora of research on the general use of recommendation systems and subjective well-being, no studies have looked directly at the effects of recommendation systems on subjective well-being. The aim of this research is to use a broad theoretical framework to demonstrate how excessive use of online recommendation systems affects users' subjective well-being. The current research adopts the situation-organism-behavior-consequence (SOBC) model (Davis \& Luthans, 1980) by expanding the established knowledge base of this topic to explain how social media overload (the situation) causes internet users 'intention to overuse recommendation systems (the organism) and how the subsequent selfconcept clarity (the behavior) results to positive or negative subjective wellbeing (the consequence).

\section{A. Theoretical Framework \\ SOBC model}

The SOBC model is based on the theory of social learning, according to Whelan et al. (2020), which notes that the different aspects of the environmental situation (S) influence the internal states of individuals or of the organism $(\mathrm{O})$, which in turn drive their behavioral responses (B) and the resulting contingent consequences $(\mathrm{C})$.

For the purpose of this study, considering overt stimuli in the environment, such as social media overload, is a central feature of the SOBC model, as it represents the situation (S) that triggers the intentions of internet users or organism (O) to excessively use recommendation systems on the internet. Selfconcept clarity is considered as the behavior (B) of internet users which indicates consumers' general satisfaction with life and its absence leads to such consumer behaviors as susceptibility to interpersonal influence, materialism, post purchase doubt, shopping as escape, and use of products as identity bolsters which consequently (C) affect users' subjective 
wellbeing. Figure 1 depicts and defines the elements of the SOBC paradigm.

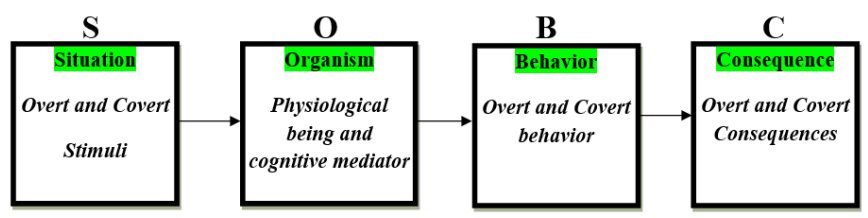

Fig. 1. S-O-B-C Model

The SOBC model is appropriate for this study since it clearly reveals how excessive use of recommendation system as a result of social media overload affects the subjective wellbeing of internet users. To begin with, very few studies have used the SOBC model to analyze the impact of digital technologies on internet users' subjective well-being. Our research will add to this body of work by integrating the more advanced SOBC model, which will expand the spectrum of theoretical insights that can be applied to the study of social media in education. Second, the SOBC model provides a structured framework for exploring how a person's self-concept clarity, or lack of it, mediate the relationship between their internet experiences and subjective well-being. The SOBC model provides a simple theoretical basis for developing and validating the research model.

\section{B. Conceptual Framework}

The proposed framework supports the study's primary aim of determining how social media overload contributes to the excessive use recommendation systems on the internet, which has an impact on users' subjective well-being. In order to better understand the relationship between recommendation systems and the subjective wellbeing of internet users, the conceptual framework or model defined in Figure 2 below shows the relationship between the different variables of the SOBC model.

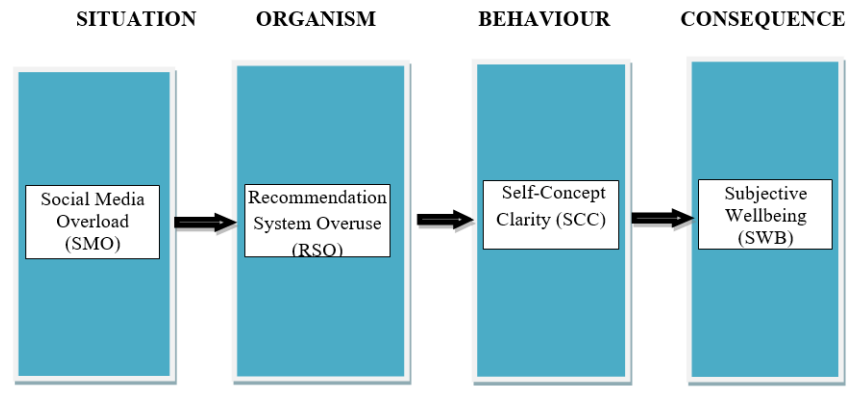

Fig. 2. Research Model

\section{Social Media Overload (SMO) and Recommendation System Overuse (RSO)}

Social media overload in the present study refers to a broad burdened condition induced by a large number of social media consumption stimuli, which is uncomfortable for a person to cope with (Yu et al., 2019). With regard to the SOBC model, SMO is conceptualized in this study as a situation in which a person's cognitive representation of their environment induces a response. People are likely to persistently seek out and recognize the use of recommendation systems on social network websites while experiencing SMO (Belkhadir et al., 2019). Therefore, the study hypothesizes that internet users are more likely to experience recommendation system overuse as they experience social media overload (SMO).

Hypothesis 1 : Social media overload is positively associated with recommendation system overuse.

\section{Recommendation System Overuse (RSO) and Self-Concept Clarity (SCC)}

An organism's behavior is an overt or covert response or action that it uses to adapt to its surroundings (Shrestha, 2017). Self-concept clarity is considered in the present study to be a covert activity that is assumed to influence the rate of use of the recommendation system. According to Lee et al. (2010), consumers with high self-concept clarity would be more hesitant to embrace product or service 
recommendations than consumers with low selfconcept clarity. In view of this, the study hypothesizes that internet users with low self-concept clarity will overuse recommendation systems on ecommerce and social media platforms.

Hypothesis 2: Overuse of Recommendation Systems is negatively associated with consumers' strength of Self- Concept Clarity.

\section{E. Self-Concept Clarity (SCC) and Subjective Wellbeing (SWB)}

A behaviour is an organism's overt or covert reaction or action to a stimulus. Because of their limited processing power, consumers often lack well-defined existing preferences, instead constructing them through ad hoc strategies based on task demands (Novemsky et al., 2007; Bettman et al., 1998). Therefore, the self-concepts of individuals also decide their choices for goods (Lee et al., 2010; Malhotra, 1988). In view of this, we assume that internet users with low self-concept clarity will exhibit over compliance to product and service recommendations (Lee et al., 2010) which can affect their subjective wellbeing.

Hypothesis 3: Self-Concept Clarity (SCC) is negatively associated with Subjective Wellbeing and act as the mediating variable between overuse of recommendation systems and subjective wellbeing.

\section{METHODS AND MATERIAL}

\section{A. Samples and procedure}

To answer the research questions and test the hypotheses, international students at the Jiangsu University in Mainland China were surveyed. The university students were chosen for the survey because they represent the most active internet users and thereby most frequently experience recommendation systems. Using web-based survey technology (Microsoft Forms), a survey form was developed and a link to it was shared with the international students who had been randomly selected to participate in the survey. When participants clicked on the link, they were directed to the survey form on the web page where the questions and instructions were provided. The participants were free to participate at a time convenient for them. Data collection began on December 18, 2020, and ended on January, 20, 2021. The link to the survey was shared with the participants on some social network platforms like Wechat and Whatsapp.

B. Measures

C. Social Media Overload:

To measure SMO, which investigated social media overload, participants were asked to rate their agreement with three items adapted from Karrwisniewski \& Lu (2010) on a 5-point Likert scale (1=strongly disagree, 5=strongly agree) in which participants responded based on their experience with recommendation systems. An example of the scale included "I am often distracted by the excessive amount of information in social media".

\section{Recommendation System Overuse:}

To measure RSO which examined recommendation system overuse, participants were asked to rate their agreement with four items on five points (1=strongly disagree, 5=strongly agree). Example of the scale included "I often choose or accept recommended products or information anytime I'm on e-commerce or social media platforms".

\section{E. Self-concept Clarity:}

The scale developed for SCC which investigated selfconcept clarity of respondents was adapted from Lee et al. (2010). Participants were asked to respond to three items on a 5-point Likert scale (1=strongly disagree, $5=$ =strongly agree) in which participants responded based on their experience with recommendation systems. An example of the scale included "On one day I might have an opinion of 
myself and on another day I might have a different opinion".

\section{F. Subjective Wellbeing:}

To measure SWB which examined subjective wellbeing, participants were asked to respond to four items adapted from Diener et al. (1984) on a 5-point Likert scale ( $1=$ strongly disagree, $5=$ strongly agree). An example of the scale included "I get dissatisfied with online experience when I excessively use recommendation systems". All the items were averaged to create a score reflecting customers' perceived novelty of recommendation systems.

\section{RESULTS AND DISCUSSION}

The purpose of the present study was to investigate the impact of excessive use of online recommendation systems on the subjective wellbeing of users. We analyzed this study by using SmartPLS 3.0 and SPSS v.22 software. The analysis of the findings was presented in this section with a view to address the purpose of the study. The survey received a total of $100 \%$ responses over a period of 33 days from the respondents. None of the questionnaire was rejected. As a result, presentation, analysis and conclusion of the study were based on 200 questionnaires administered electronically.

Comrey \& Lee (1992) proposed that a minimum of 200 valid responses is required to achieve a reasonable sampling accuracy assessment with a confidence level of 95 percent and a confident interval of 5 percent. In view of this, we believe the result of the study represent a fair assessment of the purpose of the study. The survey questionnaire was designed in simple English language for easy interpretation and also in clear language to encourage participants to offer the candid and unbiased information. Moreover, the participants were notified of the purposes and significance of the research.

\section{A. Descriptive Statistics Analysis}

This section sought to find out the background information of the respondents. The section constitutes the following; gender, age and educational level. From Table 1, the result shows that the study participated more male (54\%) than female (46\%), indicating that males are slightly dominant than females with respect to this study. The result further shows that, $42.5 \%$ of the students are within the ages of $18-25$ years, $46 \%$ within the ages of $26-39$ and $11.5 \%$ above 39 years. With regard to educational level, the study result shows that the study participated more postgraduates (62\%) than undergraduates (38\%).

Table 1: Demographic Information of Respondents

\begin{tabular}{|c|c|c|}
\hline & $\begin{array}{l}\text { Frequency } \\
\text { (N) }\end{array}$ & $\begin{array}{l}\text { Percentage } \\
(\%)\end{array}$ \\
\hline \multicolumn{3}{|l|}{ Gender } \\
\hline Male & 108 & 54 \\
\hline Female & 92 & 46 \\
\hline \multicolumn{3}{|l|}{ Age } \\
\hline $18-25$ years & 85 & 42.5 \\
\hline 26-39 years & 92 & 46 \\
\hline 40 and above & 23 & 11.5 \\
\hline \multicolumn{3}{|l|}{ Educational level } \\
\hline Undergraduate & 76 & 38 \\
\hline Postgraduate & 124 & 62 \\
\hline
\end{tabular}

Source: Field Data, 2021

\section{B. Measurement Model Assessment}

This part sought to find out the indicator reliability and internal consistency reliability of the constructs. By assessing the indicator reliability for the measurement model, factor analysis was done using the results of outer loading whilst internal consistency assessment was carried out using Cronbach's alpha and composite reliability. The summary of results can be found in Table 2 and Table 3. 
Table 2 : Indicator Reliability Assessment

\begin{tabular}{|l|c|}
\hline \multicolumn{1}{|c|}{ Construct } & Outer Loading \\
\hline Social Media Overload & 0.830 \\
SMO1 & 0.888 \\
SMO2 & 0.833 \\
SMO3 & \\
\hline Recommendation System & 0.868 \\
Overuse & 0.853 \\
RSO1 & 0.824 \\
RSO2 & \\
RSO3 & \\
\hline Self-concept Clarity & 0.757 \\
SCC1 & 0.814 \\
SCC2 & 0.827 \\
SCC3 & \\
\hline Subjective Wellbeing & 0.725 \\
SWB1 & 0.766 \\
SWB2 & 0.857 \\
SWB3 & \\
\hline
\end{tabular}

The study result in Table 2 shows that, the outer loading of each indicator is highly satisfactory. It can be realized that, each index of indicator system had a load value greater than 0.7 in the corresponding factors far beyond the acceptable value of 0.5 . None of the manifest variables were dropped since none of the variables was below 0.5 . These findings collectively indicate that the indicator system exhibits good construct validity.

The internal consistency reliability of constructs was assessed against two criteria of Cronbach's alpha and composite reliability. In cross loadings matrix, the aim is to find the item loading of each indicator which should be greater than all of the other constructs loadings. Hair Jr et al. (2017), argued that a minimum $50 \%$ of variance from manifest variable should be captured by latent variables. This means that AVE value of the construct should be greater than 0.5 . Table 3 shows the Internal Consistency Reliability and Convergent Validity.
Table 3: Internal Consistency Reliability and Convergent Validity Assessment

\begin{tabular}{|l|c|c|c|}
\hline \multicolumn{1}{|c|}{ Construct } & $\begin{array}{c}\text { Composite } \\
\text { Reliability }\end{array}$ & $\begin{array}{c}\text { Cronbac } \\
\text { h's } \\
\text { Alpha }\end{array}$ & AVE \\
\hline $\begin{array}{l}\text { Social Media } \\
\text { Overload }\end{array}$ & 0.887 & 0.755 & 1.086 \\
\hline $\begin{array}{l}\text { Recommendatio } \\
\text { n System } \\
\text { Overuse }\end{array}$ & 0.885 & 0.795 & 1.080 \\
\hline $\begin{array}{l}\text { Self-concept } \\
\text { Clarity }\end{array}$ & 0.842 & 0.732 & 0.960 \\
\hline $\begin{array}{l}\text { Subjective } \\
\text { Wellbeing }\end{array}$ & 0.827 & 0.724 & 0.923 \\
\hline
\end{tabular}

From Table 3, it can be realized that the Cronbach's alpha values for the 10 constructs are within 0.714 and 0.848 which are all above the value of 0.7 . This suggests that, all constructs met the acceptable values for criteria of Cronbach's alpha which should be more than 0.7. Again, it can be realized that the composite reliability values for the four (4) constructs are all above the acceptable value of 0.7 . This suggests that, all constructs met the acceptable values for criteria of composite reliability which should be more than 0.7 . These findings indicate that the indicator system manifests good internal consistency and reliability.

Also, the values of AVE as shown in Table 3 are all well above the threshold of 0.50 and indicate that the measurement model has no issues regarding its convergent validity. As exhibited in Table 3, the root square of each construct's AVE value is higher than any other construct which correlated to it. Hence, Fornell-Larcker criterion provides evidence for the constructs' discriminant validity.

C. Summary of Structural model

Table 4 shows the significance testing results of the structural model and path coefficients of the defined constructs. The co-efficient of determination $\left(\mathrm{R}^{2}\right)$ values of recommendation system overuse, self- 
concept clarity and subjective wellbeing which are the three regress of this study were $0.65,0.58$ and
0.63 respectively. This indicates that the constructs represent a good fit for the model.

Table 4: Summary of Structural Equation Model

\begin{tabular}{|l|l|c|c|c|c|}
\hline Hypothesis & Description & $\begin{array}{c}\text { Path Coefficient } \\
(\beta)\end{array}$ & $\mathbf{t}_{\text {cal }}$ & $\mathrm{p}|>|$ & Results \\
\hline Hypothesis 1 & SMO $\rightarrow$ RSO & 0.427 & 7.230 & $0.000^{\cdots *}$ & Supported \\
\hline Hypothesis 3 & RSO $\rightarrow$ SCC & 0.201 & 3.403 & $0.001^{* *}$ & Supported \\
\hline Hypothesis 4 & SCC $\rightarrow$ SWB & 0.107 & 1.811 & $0.058^{* *}$ & Supported \\
\hline
\end{tabular}

Note- SMO: social media overload, RSO: recommendation system overuse, SCC: self-concept clarity, SWB: subjective wellbeing "significant at $10 \%$, "significant at $5 \%$, "'significant at $1 \%$.

\section{IV.CONCLUSION}

This paper examines the impact of recommendation system overuse on the subjective wellbeing of internet users by employing the Situation-OrganismBehavior-Consequence (SOBC) model. The results of this study indicate that all proposed hypotheses are valid and supported, and therefore all proposed relationships between constructs were statistically confirmed. In particular, it is evident by the result that, social media overload positively affects recommendation system overuse which consequently affect users subjective wellbeing based on their level of self-concept clarity.

\section{A. Implications of Present Study}

The results of this study provide both managerial and academic contributions. In terms of managerial contribution, the results provide concrete insight for current and prospective managers to better understand how the overuse of recommendation systems can affect the subjective wellbeing of customers. In view of this, developers and managers should be mindful of the importance of recognizing the wellbeing of consumers of recommendation systems and enhancing the overall usability and efficiency of the algorithm, so that the use or overuse of recommendation systems would leave no or reduce adverse effect on users.
This study also provides some academic contributions. It extended the Situation Organism Behavior Consequence (SOBC) model to the context of recommendation systems and subjective wellbeing. While the SOBC has been widely used to examine antecedents of organizational behavioral intentions of workers, the present study is one of the few studies to apply the framework to recommendation systems.

\section{B. Limitations and Future Research}

The limitations of this study mostly regard the size and composition of the sample. The questionnaire was distributed among undergraduate and postgraduate students of a university in China. The limited sample may therefore constrain the generalizability of the research result to young adults in a university. Again, although young adults tend to have extensive online shopping experiences, our results do not completely address the entire customers' experience with recommendation systems on the internet. It would have been preferable if samples represented more varied age groups.

A proposal for future research is to undertake a study on a larger group of online customers in order to include more participants of different ages and backgrounds. Comparisons between them will be 
appropriate by observing various customer segments. Furthermore, we suggest that future studies adopt new models and strategies to examine the effects of recommendation system overuse on users.

\section{ACKNOWLEDGEMENTS}

The authors thank all the respondents for availing themselves for the survey. Also, this research was supported by:

1. China National Statistical Research Project (2016LY96)

2. Teaching Reform and Research Project of Jiangsu University (2017JGYB008)

\section{REFERENCES}

[1]. Belkhadir, I., Omar, E. D., \& Boumhidi, J. (2019). An intelligent recommender system using social trust path for recommendations in web-based social networks. Procedia Computer Science, $\quad 148,181-190$. https://doi.org/10.1016/j.procs.2019.01.035

[2]. Bettman, J. R., Luce, M. F., \& Payne, J. W. (1998). Constructive Consumer Choice Processes. Journal of Consumer Research, 25(3), 187-217. https://doi.org/10.1086/209535

[3]. Butzer, B., \& Kuiper, N. A. (2006). Relationships between the frequency of social comparisons and self-concept clarity, intolerance of uncertainty, anxiety, and depression. Personality and Individual Differences, $\quad 41(1)$, 167-176. https://doi.org/10.1016/j.paid.2005.12.017

[4]. Campbell, J. D., Trapnell, P. D., Heine, S. J., Katz, I. M., Ravallee, L. F., \& Lehman, D. R. (1996). Self-concept clarity: Measurement, personality correlates, and cultural boundaries. Journal of Personality and Social Psychology, 70(1), 141-156.
[5]. Comrey, A. L., \& Lee, H. B. (1992). A first course in factor analysis. Hillsdale, NJ: Lawrence Erlbaum Associates.

[6]. Davis, T. R. V., \& Luthans, F. (1980). A Social Learning Approach to Organizational Behavior. Academy of Management Review, 5(2), 281290. https://doi.org/10.5465/amr.1980.4288758

[7]. Diener, E., Lucas, R. E., \& Oishi, S. (1984). Subjective Well-Being-The Science of Happiness and Life Satisfaction. Psychological Bulletin, 542-575.

[8]. Hadj Sassi, M. S., Jedidi, F. G., \& Fourati, L. C. (2019). A New Architecture for Cognitive Internet of Things and Big Data. Procedia Computer Science, 159, 534-543. https://doi.org/10.1016/j.procs.2019.09.208

[9]. Hair Jr, J. F., Hult, G. T. M., Ringle, C., \& Sarstedt, M. (2017). A primer on partial least squares structural equation modeling (PLSSEM). Sage Publications.

[10]. Hu, G. N., Dai, X. Y., Song, Y., Huang, S. J., \& Chen, J. J. (2015). A synthetic approach for recommendation: Combining ratings, social relations, and reviews. In Proc. of IJCAI, 17561762.

[11]. Isinkaye, F. O., Folajimi, Y. O., \& Ojokoh, B. A. (2015). Recommendation systems: Principles, methods and evaluation. Egyptian Informatics Journal, 16(3), 261-273. https://doi.org/10.1016/j.eij.2015.06.005

[12]. Karr-wisniewski, P., \& Lu, Y. (2010). Computers in Human Behavior When more is too much: Operationalizing technology overload and exploring its impact on knowledge worker productivity. COMPUTERS IN HUMAN BEHAVIOR, 1-12. https://doi.org/10.1016/j.chb.2010.03.008

[13]. Lee, G., Lee, J., \& Sanford, C. (2010). The roles of self-concept clarity and psychological reactance in compliance with product and service recommendations. Computers in Human Behavior, 26(6), 1481-1487. https://doi.org/10.1016/j.chb.2010.05.001 
[14]. Liu, P., Tov, W., Kosinski, M., Stillwell, D. J., \& Qiu, L. (2015). Do Facebook Status Updates Reflect Subjective Well-Being? Cyberpsychology, Behavior, and Social Networking, 18(7), 373-379. https://doi.org/10.1089/cyber.2015.0022

[15]. Luhmann, M. (2017). Using Big Data to study subjective well-being. Current Opinion in Behavioral Sciences, 18, 28-33. https://doi.org/10.1016/j.cobeha.2017.07.006

[16]. Malhotra, N. K. (1988). Self concept and product choice: An integrated perspective. Journal of Economic Psychology, 9(1), 1-28. https://doi.org/10.1016/0167-4870(88)90029-3

[17]. Mittal, B. (2015). Self-concept clarity: Exploring its role in consumer behavior. Journal of Economic Psychology, 46, 98-110. https://doi.org/10.1016/j.joep.2014.11.003

[18]. Novemsky, N., Dhar, R., Schwarz, N., \& Simonson, I. (2007). Preference Fluency in Choice. Journal of Marketing Research, 44(3), 347-356. https://doi.org/10.1509/jmkr.44.3.347

[19]. Ramos, G., Boratto, L., \& Caleiro, C. (2020). On the negative impact of social influence in recommender systems: A study of bribery in collaborative hybrid algorithms. Information Processing \& Management, 57(2), 102058. https://doi.org/10.1016/j.ipm.2019.102058

[20]. Ricci, F., Rokach, L., \& Shapira, B. (2015). Recommender Systems: Introduction and Challenges. In Recommender Systems Handbook (pp. 1-34). Springer US. https://doi.org/10.1007/978-1-4899-7637-6_1

[21]. Sharma, L., \& Gera, A. (2013). A Survey of Recommendation System: Research. International Journal of Engineering Trends and Technology (IJETT), 4(5), 1989-1992.

[22]. Shrestha, P. (2017). Overt vs Covert Behavior," in Psychestudy. https://www.psychestudy.com/behavioral/beha vior/overt-vs-covert

[23]. Slocum-Gori, S. L., Zumbo, B. D., Michalos, A. C., \& Diener, E. (2009). A Note on the
Dimensionality of Quality of Life Scales: An Illustration with the Satisfaction with Life Scale (SWLS). Social Indicators Research, 92(3), 489496. https://doi.org/10.1007/s11205-008-9303-y

[24]. Smith, M., Wethington, E., \& Zhan, G. (1996). Self-Concept Clarity and Preferred Coping Styles. Journal of Personality, 64(2), 407-434. https://doi.org/10.1111/j.14676494.1996.tb00516.x

[25]. Tov, W. (2012). Institutional Knowledge at Singapore Management University Daily experiences and well-being: Do memories of events matter ? 26, 1371-1389.

[26]. Whelan, E., Islam, A. K. M. N., \& Brooks, S. (2020). Applying the SOBC paradigm to explain how social media overload affects academic performance. Computers \& Education, 143, 103692.

https://doi.org/10.1016/j.compedu.2019.103692

[27]. Yu, L., Shi, C., \& Cao, X. (2019). Understanding the Effect of Social Media Overload on Academic Performance: A Stressor-StrainOutcome Perspective. 6, 2657-2666. https://doi.org/10.24251/HICSS.2019.320

[28]. Zhao, W., Ma, H., Li, Z., Ao, X., \& Li, N. (2020). Improving social and behavior recommendations via network embedding. Information Sciences, 516, 125-141. https://doi.org/10.1016/j.ins.2019.12.038

\section{Cite this article as :}

Morrant Hemans, Dickson Kofi Wiredu Ocansey, "The Impact of Recommendation System Overuse on the Subjective Wellbeing of Internet Users", International Journal of Scientific Research in Science, Engineering and Technology (IJSRSET), Online ISSN : 2394-4099, Print ISSN : 2395-1990, Volume 8 Issue 1, pp. 239-247, January-February 2021. Available at doi : https://doi.org/10.32628/IJSRSET218156 Journal URL : https://ijsrset.com/IJSRSET218156 